\title{
$\beta$-hydroxybutyrate does not alter the effects of glucose deprivation on breast cancer cells
}

\author{
RYLEE MALDONADO ${ }^{1}$, CHLOE ADRIENNA TALANA ${ }^{1}$, CASSAUNDRA SONG $^{1,2}$, ALYSSA DIXON $^{1}$, \\ KAHEALANI UEHARA $^{1,3}$ and MICHAEL WEICHHAUS ${ }^{1}$ \\ ${ }^{1}$ Laboratory of Molecular Cancer Research, School of Natural Sciences and Mathematics, \\ Chaminade University of Honolulu, Honolulu, HI 96816; ${ }^{2}$ Department of Biomedical Sciences, Joan C. Edwards School \\ of Medicine, Marchall University, Huntington, WV 25755; ${ }^{3}$ Biochemistry and Molecular Biophysics Graduate Group, \\ University of Pennsylvania, Perelman School of Medicine, Philadelphia, PA 19104, USA
}

Received July 15, 2020; Accepted September 29, 2020

DOI: $10.3892 / \mathrm{ol} .2020 .12326$

\begin{abstract}
Ketogenic diets have the potential to lower glucose availability to cancer cells. However, the effect that the resulting increase in ketone bodies has on cancer cells is not fully understood. The present study explored the effect of $\beta$-hydroxybutyrate (BHB) on glucose-deprived MCF-7 and T47D breast cancer cells. Cell proliferation was decreased in response to lower glucose conditions, which could not be rescued consistently by 10 or $25 \mathrm{mM}$ BHB supplementation. In addition, gene expression levels were altered when cells were glucose deprived. Reducing glucose availability of cancer cells to $225 \mathrm{mg} / \mathrm{l}$ for 4 days significantly decreased the expression of 113 genes and increased the expression of 100 genes in MCF-7 breast cancer cells, and significantly decreased the expression of 425 genes and increased the expression of 447 genes in T47D breast cancer cells. Pathway enrichment analysis demonstrated that glucose deprivation decreased activity of the Hippo-Yap cell signaling pathway in MCF-7 breast cancer cells, whereas it increased the expression of genes in the NRF2-pathaway and genes regulating ferroptosis in T47D breast cancer cells. Treatment of glucose-deprived cells with 10 or $25 \mathrm{mM}$ BHB significantly changed the expression of 14 genes in MCF-7 breast cancer cells and 40 genes in T47D breast cancer cells. No significant pathway enrichment was detected when glucose-deprived cells were treated with BHB. Both cell lines expressed the enzymes (OXCT1/2, BDH1 and ACAT1/2) responsible for metabolizing BHB to acetyl-CoA, yet expression of these enzymes was not altered by either glucose deprivation or BHB treatment. In the publicly available The
\end{abstract}

Correspondence to: Dr Michael Weichhaus, Laboratory of Molecular Cancer Research, School of Natural Sciences and Mathematics, Chaminade University of Honolulu, 3140 Waialae Avenue, Honolulu, HI 96816, USA

E-mail: michael.weichhaus@chaminade.edu

Key words: breast cancer cells, ketone bodies, $\beta$-hydroxybutyrate, ferroptosis, Hippo-Yap
Cancer Genome Atlas (TCGA), increased expression of ketone body-catabolizing enzymes was observed in various types of cancer based on mRNA expression z-scores. Increased expression of BDH1 and ACAT1 significantly decreased overall survival of patients with breast cancer in TCGA studies, while decreased OXCT1 expression non-significantly decreased overall survival. In conclusion, neither MCF-7 nor T47D breast cancer cells were affected by BHB during glucose deprivation; however, screening of tumors for activation of ketone body-metabolizing enzymes may be able to identify patients that will benefit from ketogenic diet interventions.

\section{Introduction}

The energy metabolism of cancer cells and breast cancer cells in particular is different than that of most non-proliferating epithelial cells $(1,2)$. This altered energy metabolism, variously termed the Warburg effect or aerobic glycolysis, is characterized by breast cancer cells importing vast amounts of glucose from the blood, metabolizing it through the glycolysis pathway and releasing most of the produced pyruvate as lactate. While this type of metabolism is found in certain anaerobic organisms and temporarily under hypoxic conditions in mammalian cells, it is a permanent feature for almost all cancer cells, even in the presence of sufficient oxygen levels, hence 'aerobic' glycolysis. The discovery of this peculiar effect has been made almost a century ago (3), however its potential for therapeutic exploitation has only recently started to be elucidated. In 1995, Nebeling and colleagues (4) placed two pediatric patients with advanced astrocytoma on a low carbohydrate diet, with the idea to reduce the availability of glucose to the cancer cells. Both patients went into remission and remained progression-free while on the diet. While a small case study, it indicated that glucose deprivation through dietary adaptation (ketogenic diets or low-carbohydrate diets) could be detrimental to tumor and be useful for cancer patient treatment. Ketogenic diets are characterized by replacing the almost all calories from carbohydrate with lipids and protein, with calories from carbohydrates as low as 5\% of total calories (5). These diets are used clinically to treat refractory epilepsy, obesity, and type-2 diabetes (6-8). This leads to hepatic activation of ketone body 
production as alternative fuel primarily for the central nervous system, ketone bodies however can be used by all cell types as metabolic fuel (9). Since the 1995 case study report ketogenic diets have been trialed for their effect against tumors in both mouse and human studies with varying results (10-13). In vitro studies have mainly focused on the role of ketone bodies, specifically $\beta$-hydroxybutyrate (BHB) as a treatment of cancer cells under regular glucose conditions $(14,15)$. They show similar discrepancies as clinical studies in that some show no effect on breast cancer cell behavior $(15,16)$, while others do demonstrate reduced survival or metabolic changes in cancer cells $(17,18)$. However, if breast cancer cells artificially express enzymes for ketone body metabolism, they are able to survive and even thrive in low glucose conditions (19). Similar effects were observed in glioblastoma patients that failed to respond to ketogenic diet interventions. Their tumors had developed the ability to metabolize ketone bodies (20). Even if ketone bodies are not metabolized for energy, recent research demonstrates that BHB may also act as a signaling molecule that could potentially have other effects on breast cancer cells besides being an inert metabolic substrate (21). Since ketogenic diets are increasingly used in clinical practice for adjuvant cancer treatment, there is a need to better understand how cancer cells react when confronted with ketogenic environments.

Here we present the results of exposing luminal-A type breast cancer cells MCF-7 and T47D (22) to ketogenic environments. As such we reduced glucose exposure to these cells to $5 \%$ of their usual amount and supplemented with up to $25 \mathrm{mM}$ BHB. We examined the breast cancer cell's rate of proliferation and analyzed gene expression changes under these conditions.

\section{Materials and methods}

Cell culture. Human breast cancer cell lines MCF-7 (cat. no. HTB-22) and T47D (cat no. HTB-133) were purchased from the American Tissue Culture Collection (ATCC) and routinely maintained in DMEM (Gibco; Thermo Fisher Scientific, Inc.) with 10\% FBS (Atlanta Biologicals; R\&D Systems), 2 mM glutamine (Gibco; Thermo Fisher Scientific, Inc.) and $50 \mathrm{ng} / \mathrm{ml}$ gentamycin (Lonza Biologicals). Human breast epithelial cells MCF-10A (cat. no. CRL-10317) cells were purchased from ATCC and routinely maintained in DMEM/F-12 Medium (Gibco; Thermo Fisher Scientific, Inc.) supplemented with 5\% Horse Serum (Sigma-Aldrich; Merck KGaA), $10 \mu \mathrm{g} / \mathrm{ml}$ human insulin (Sigma-Aldrich; Merck KGaA), $0.5 \mu \mathrm{g} / \mathrm{ml}$ hydrocortisone (Sigma-Aldrich; Merck KGaA) $20 \mu \mathrm{g} / \mathrm{ml}$ human epidermal growth factor (Invitrogen; Thermo Fisher Scientific, Inc.), $100 \mathrm{ng} / \mathrm{ml}$ cholera toxin (Sigma-Aldrich; Merck KGaA), $50 \mathrm{ng} / \mathrm{ml}$ gentamycin (Lonza). Sodium $\beta$-hydroxybutyrate was purchased from Sigma-Aldrich; Merck KGaA. Cell lines were incubated at $37^{\circ} \mathrm{C}$ humidified $5 \% \mathrm{CO}_{2}$-supplemented air. Cell lines were routinely maintained in $75 \mathrm{~cm}^{2}$ tissue culture flasks with filtered lids (Thermo Fisher Scientific, Inc.) and sub-cultured when reaching approximately $80 \%$ confluence. Cell cultures were inspected daily for visible contamination and consistent growth rates. After purchase from ATCC, cell lines were maintained exclusively within the research group and handled by qualified researchers. The cell culture facility is only accessible to qualified researchers and does not maintain HeLa cells.
Cell stock were stored in a locked designated cryo-vessel and inventory records were maintained including clear labeling of cryo-tubes and flasks with full cell line name, date, passage number and initials of the researcher. Trypsin (0.25\%) (Gibco; Thermo Fisher Scientific, Inc.) was maintained in $10 \mathrm{ml}$ aliquots at $-20^{\circ} \mathrm{C}$ in sterile $15 \mathrm{ml}$ falcon tubes (Thermo Fisher Scientific, Inc.). Fetal bovine serum (R\&D Systems) was maintained in $50 \mathrm{ml}$ aliquots at $-20^{\circ} \mathrm{C}$ in sterile $50 \mathrm{ml}$ falcon tubes (Thermo Fisher Scientific, Inc.). Cells were routinely maintained in mycoplasma suppressing antibiotic gentamycin and prepared medium was used for a maximum of three weeks. Experiments on cell lines were performed within 25 passages of receipt from ATCC.

Cell proliferation. In 96-well dishes, $5 \times 10^{3}$ cells were plated in $100 \mu \mathrm{l}$ of regular DMEM and incubated overnight. After removing all medium, cells were treated with decreasing glucose concentrations $[4.5,2.25,1.5,1 ., 0.75,0.5,0.225$, $0.125,0$ (all in $\mathrm{g} / \mathrm{l}$ )] alone, or in combination with 10 or $25 \mathrm{mM}$ BHB for either 48 or $72 \mathrm{~h}$. Four hours prior to analysis, cells were supplemented with $1 \mathrm{mg} / \mathrm{ml}$ MTT (Thermo Fisher Scientific, Inc.) solution. After finalizing the indicated treatment periods, all media was removed from the wells and $200 \mu \mathrm{l}$ DMSO (Sigma-Aldrich; Merck KGaA) was added to each well. After incubating the plates at room temperature for 15 min with gentle shaking, absorbance of each well was read at $540 \mathrm{~nm}$ using a BioRad Mark plate reader. For MCF-7 and MCF-10A at least three experiments with six replicates for each treatment were performed, while a single experiment with six replicates for each treatment was performed for T47D cells.

In $10 \mathrm{~cm}$ dishes, $10^{5} \mathrm{MCF}-10 \mathrm{~A}$ breast epithelial cells or MCF-7 breast cancer cells were plated and treated for 18 days with regular DMEM and either $225 \mathrm{mg} / 1$ glucose or $225 \mathrm{mg} / \mathrm{l}$ glucose with 10 or $25 \mathrm{mM} \beta$-hydroxybutyrate (BHB). Medium and treatment conditions were renewed every four days. Cells were counted every day using Trypan Blue exclusion counts. Cells were observed with a Nikon Microscope and brightfield pictures were captured at x40 magnification daily. Experiments were performed in duplicates for a total of three experiments.

RNA sequencing. In $10 \mathrm{~cm}$ dishes, $1 \times 10^{6} \mathrm{MCF}-7$ or T47D breast cancer cells were incubated in regular DMEM medium or treated with $225 \mathrm{mg} / 1$ (5\% of glucose in regular DMEM medium) alone or in combination with $10 \mathrm{mM} \mathrm{BHB}$ or $25 \mathrm{mM}$ BHB for four days for a total of two experiments. Then total RNA was extracted using Qiagen's RNeasy Mini Kit (Qiagen) and submitted for RNA sequencing using Psomagen's mRNA sequencing service, which included library development and delivered in excess of $6 \times 10^{6} 150$ bp pair-ended reads per sample (Psomagen Inc.). We performed two independent experiments for each cell line and treatment condition.

RNA sequence analysis. After obtaining sequences, abundances were quantified from raw fastq files and mapped against human Ensembl v96 transcriptomes pre-indexed files using Lior Pachter's kallisto (23). Abundance files were analyzed using Bioconductor's DESeq2 (version 1.28.1) package for R (24). Data quality control was established using Bioconductor's principal component analysis (PCA) to 
detect variance within samples. PCA results are displayed as two-dimensional graphs showing contribution of the highest component variance in each sample comparison. Results were reduced for expression changes of over 1.5-fold and analyzed for false discoveries as previously described (25). P-adjusted values of $<0.05$ were considered to be statistically significant. We used Bioconductor version $3.11(26,27)$ and $\mathrm{R}$ version 4.0 (28) on RStudio version 1.3.959.

Gene ontology and over representation analysis. Gene ontology analysis was performed using the WikiPathway package (29) for $\mathrm{R}$ and further processed for pathway enrichment (30) in Cytoscape version 3.8.0 (31), using a hypergeometric test with a Benjamini-Hochberg false discovery rate correction (32). A P-value of less than 0.05 was used to identify enriched pathways. Selected pathways that had been identified were visualized using WikiPathway (33) or using clusterProfiler for pathway visualization (34).

Comparison of catabolic ketone metabolism enzymes in The Cancer Genome Atlas. We queried The Cancer Genome Atlas (TCGA) PanCancer Atlas studies at cBioPortal (cBioPortal. org) $(35,36)$ for expression of BDH1, OXCT1, and ACAT1 genes encoding enzymes for catabolic metabolism of ketone bodies. This returned 32 studies with 10,953 patient samples. Additionally, we selected the Breast Invasive Carcinoma (TCGA, PanCancer Atlas) database and plotted mRNA expression levels (high: Above 1.5-fold; low: Below -1.5-fold expression based on mRNA expression $\mathrm{z}$-scores relative to all samples, with a z-score threshold of \pm 2.0 ) of BDH1, OXCT1 and ACAT1 against overall survival.

Statistical analysis. Cell proliferation data from MTT assays are presented as bars representing interquartile range including the observed median (horizontal line). Whiskers represent highest and lowest observed values. Outliers detected by Tukey's method are shown in each graph if present.

Cell proliferation data were analyzed by two-way ANOVA, followed by Holm-Sidak post-hoc corrections to test for statistical differences of survival of each condition (control; $25 \mathrm{mM} \mathrm{BHB}$ ) at any glucose concentration compared to regular glucose concentration of $4.5 \mathrm{~g} / \mathrm{l}$. Cell proliferation data were also analyzed using multiple t-tests with Holm-Sidak corrections for multiple analyses to test for statistical differences between non-BHB and BHB treated samples at every glucose concentration. Cell proliferation data in Fig. S1 are presented as the mean of two independent experiment with six replicates. Error bars represent standard deviation. Cell proliferation data in Fig. S1 were analyzed for statistical differences between each BHB concentration and control using Dunnett's corrections following two-way ANOVA for T47D cells and MCF-7 cells and Tukey correction following one-way ANOVA for MCF-10A cells. Cell count data (Fig. 1G) are presented by means of three experiments with two replicates per experiments. Error bars were omitted for clarity. Cell count data were analyzed by multiple t-tests using the Holm-Sidak method to determine statistical significance for count differences between all three experimental conditions on each day (control; no glucose no BHB; no glucose $25 \mathrm{mM}$ BHB). A P-value of $<0.05$ was considered statistically significant. Statistical analysis was performed using GraphPad Prism software v.8.4.3 (GraphPad Software, Inc.). Statistical analysis of the RNA sequencing workflow was integrated into the DESeq2 analysis as previously described (24). Kaplan-Meier curves were drawn to compare overall survival in patients with breast cancer where tumors express high or low mRNA levels of BDH1, OXCT1 or ACAT1. A log rank test was used for detection of statistical differences of patient survival data was performed using cBioPortal built-in analysis. A P-value of $<0.05$ was considered statistically significant.

\section{Results}

Ketone bodies are tolerated by breast cancer cells. We performed kill curves of $\mathrm{BHB}$ on all cell lines of up to $200 \mathrm{mM}$ using MTT assays (Fig. S1). No significant impact on cell proliferation was observed for BHB concentrations of up $25 \mathrm{mM}$, which was chosen as the highest BHB treatment concentration, while $10 \mathrm{mM}$ BHB corresponds to a high physiological level of BHB in medically therapeutic uses of ketogenic diets (37).

Ketone bodies do not rescue breast cancer cells during glucose deprivation. MCF-7 and T47D breast cancer cells and MCF-10A breast epithelial cells were incubated in decreasing glucose concentrations with $25 \mathrm{mM}$ BHB for $48 \mathrm{~h}$ or $72 \mathrm{~h}$ (Fig. 1A-F). Cell proliferation decreased in both cell lines with decreasing glucose concentrations. For MCF-7 cells, cell proliferation significantly decreased after reducing glucose concentrations to $1 \mathrm{~g} / \mathrm{l}$ and below glucose concentrations of $250 \mathrm{mg} / 1$ when compared to proliferation at $4.5 \mathrm{~g} / 1$ glucose after $48 \mathrm{~h}$. When supplementing with $25 \mathrm{mM} \mathrm{BHB}$ cell proliferation decreased significantly after treatment with $2.25 \mathrm{~g} / 1$ glucose and below compared to proliferation at $4.5 \mathrm{~g} / \mathrm{l}$ glucose and $25 \mathrm{mM}$ BHB after $48 \mathrm{~h}$. There was no significant difference in cell proliferation between not BHBand BHB-supplemented MCF-7 cells at any of the different glucose treatment concentrations (Fig. 1A). Cell proliferation significantly decreased after treatment of MCF-7 cells with reduced glucose of $250 \mathrm{mg} / \mathrm{l}$ and below compared to proliferation at $4.5 \mathrm{~g} / \mathrm{l}$ glucose after $72 \mathrm{~h}$. When supplementing with $25 \mathrm{mM}$ BHB cell proliferation decreased significantly after treatment with $500 \mathrm{mg} / \mathrm{l}$ glucose and below compared to proliferation at $4.5 \mathrm{~g} / \mathrm{l}$ glucose and $25 \mathrm{mM} \mathrm{BHB}$ after $72 \mathrm{~h}$. We observed a significant difference in proliferation between not-BHB- and BHB-supplemented MCF-7 cells after treatment with $1 \mathrm{~g} / 1$ glucose (Fig. 1B).

For T47D cells, cell proliferation significantly decreased after reducing glucose concentrations below $750 \mathrm{mg} / \mathrm{l}$ when compared to proliferation at $4.5 \mathrm{~g} / 1$ glucose after $48 \mathrm{~h}$. When supplementing with $25 \mathrm{mM}$ BHB cell proliferation decreased significantly after treatment with $1 \mathrm{~g} / 1$ glucose and below compared to proliferation at $4.5 \mathrm{~g} / 1$ glucose and $25 \mathrm{mM} \mathrm{BHB}$ after $48 \mathrm{~h}$. There was a significantly higher levels of cell proliferation in BHB-supplemented T47D cells compared to not-BHB-supplemented cells at very low glucose concentration $(0 \mathrm{~g} / \mathrm{l}$ and $125 \mathrm{mg} / \mathrm{l})$ (Fig. 1C), indicating that BHB may be metabolized by these cells when there is no glucose present. Cell proliferation significantly decreased after treatment of T47D cells with reduced glucose concentrations of $1 \mathrm{~g} / \mathrm{l}$ and 

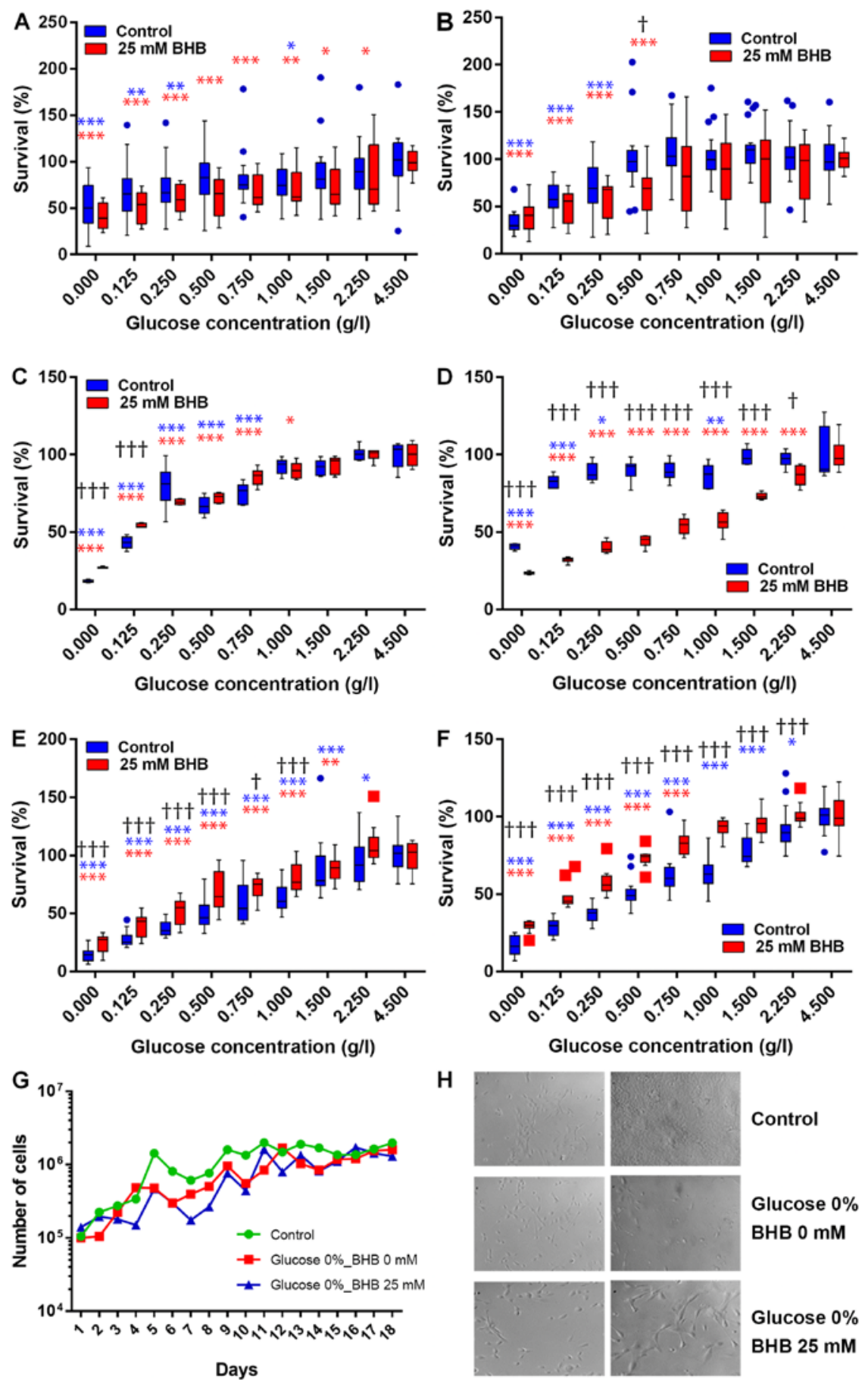

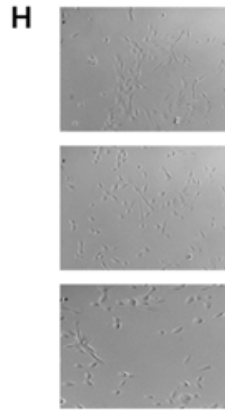

Day 1

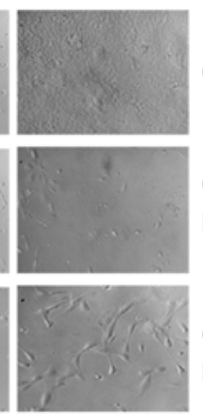

Day 18

Control

Glucose $0 \%$

BHB $0 \mathrm{mM}$

Glucose $0 \%$

BHB $25 \mathrm{mM}$

Figure 1. Cell proliferation analysis in glucose starved human cells. (A and B) MCF-7, (C and D) T47D human breast cancer cells and (E and F) MCF-10A human breast epithelial cells were incubated in decreasing amounts of glucose alone (blue) or in the presence of $25 \mathrm{mM} \mathrm{BHB}$ (red) for (A, C and E) $48 \mathrm{~h}$ or (B, D and F) $72 \mathrm{~h}$. Bars represent interquartile range including the observed median (horizontal line). Whiskers represent highest and lowest observed values. Outliers detected by the Tukey-method are indicated by blue circles and red squares for not-BHB- and BHB-supplemented cells, respectively. "Indicate significant difference of the respective treatment [not-BHB supplemented (blue); BHB supplemented (red)] between the glucose concentration it is associated with and the respective cell proliferation level observed at $4.5 \mathrm{~g} / 1$ glucose as calculated by two-way ANOVA followed by Holm-Sidak post hoc corrections for multiple comparisons. Indicate significant difference between not-BHB- and BHB-supplemented cells at the specific glucose concentration as calculated by multiple t-tests with Holm-Sidak method corrections. Significant levels: ${ }^{* / /} \mathrm{P}<0.05 ;{ }^{* *} \mathrm{P}<0.01 ;{ }^{* * *} /{ }^{\prime \dagger}+\mathrm{P}<0.001$. (G) MCF-7 breast cancer cells were incubated in regular high-glucose DMEM medium (green), in glucose depleted DMEM medium (red) or in glucose depleted medium supplemented with $25 \mathrm{mM}$ BHB (blue) for up to 18 days. Line graphs represent mean cell count of two independent experiments. Error bars for standard deviation were omitted for clarity. There were no significant differences in proliferation at any time-point. (H) Brightfield pictures at $\mathrm{X} 40$ magnification of MCF-10A human breast epithelial cells after 18 days of exposure to glucose deprivation with or without BHB supplementation. BHB, $\beta$-hydroxybutyrate.

below glucose concentrations of $250 \mathrm{mg} / \mathrm{l}$ when compared to proliferation at $4.5 \mathrm{~g} / \mathrm{l}$ glucose after $72 \mathrm{~h}$. When supplementing with $25 \mathrm{mM}$ BHB cell proliferation decreased significantly after treatment with $2.25 \mathrm{~g} / 1$ glucose and below compared to proliferation at $4.5 \mathrm{~g} / 1$ glucose and $25 \mathrm{mM} \mathrm{BHB}$ after $72 \mathrm{~h}$. Conversely to $48 \mathrm{~h}$ treatments, there was significantly 
lower proliferation in BHB-supplemented cells compared to not-BHB supplemented cells at all glucose treatment conditions of $2.25 \mathrm{~g} / 1$ and below (Fig. 1D).

We were interested if extending the incubation time beyond $72 \mathrm{~h}$ would demonstrate adaptation of the breast cancer cells to the ketogenic environment as a reflection of the transition period observed during ketogenic diets in patients. When using cell counts, we did not find any significant difference between treatment conditions and control (Fig. 1G).

For MCF-10A cells, cell proliferation significantly decreased after reducing glucose concentrations below $2.25 \mathrm{~g} / 1$ when compared to proliferation at $4.5 \mathrm{~g} / 1$ glucose after $48 \mathrm{~h}$. When supplementing with $25 \mathrm{mM}$ BHB cell proliferation decreased significantly after treatment with $1.5 \mathrm{~g} / \mathrm{l}$ glucose and below compared to proliferation at $4.5 \mathrm{~g} / 1$ glucose and $25 \mathrm{mM}$ BHB after $48 \mathrm{~h}$. There was a significantly higher levels of cell proliferation in BHB-supplemented MCF-10A cells compared to not-BHB-supplemented cells at glucose concentration of $1 \mathrm{~g} / \mathrm{l}$ and below (Fig. 1E). Cell proliferation significantly decreased after treatment of MCF-10A cells with reduced glucose concentrations of $2.25 \mathrm{~g} / 1$ and below when compared to proliferation at $4.5 \mathrm{~g} / 1$ glucose after $72 \mathrm{~h}$. When supplementing with $25 \mathrm{mM}$ BHB cell proliferation was significantly decreased after treatment with $750 \mathrm{mg} / \mathrm{l}$ glucose and below compared to proliferation at $4.5 \mathrm{~g} / 1$ glucose and $25 \mathrm{mM}$ BHB after $72 \mathrm{~h}$. Complementary to $48 \mathrm{~h}$ treatments, there was significantly higher proliferation in BHB-supplemented cells compared to not-BHB supplemented cells at all glucose treatment conditions of $2.25 \mathrm{~g} / \mathrm{l}$ and below (Fig. 1F).

When treatment times of MCF-10A breast epithelial cells was extended to 18 days we observed that glucose deprivation decreased proliferation, but the BHB supplementation increased proliferation and cell size (Fig. 1H). This indicates that non-cancerous epithelial cells can metabolize ketone bodies such as BHB and would be able to survive under ketogenic conditions.

Differential gene expression in low glucose environments. We performed RNA sequencing analysis on MCF-7 and T47D breast cancer cells and compared treatments in three pairs per cell line. The first comparison examined the effect of low glucose conditions on gene expression changes in breast cancer cells without BHB supplementation compared to cells grown in normal $(4.5 \mathrm{~g} / \mathrm{l})$ glucose concentrations. We observed that for MCF-7 breast cancer cells 221 genes had at least 1.5-fold difference in expression and less than $0.05 \mathrm{p}$-adjusted value and 1182 genes for T47D breast cancer cells (Fig. 2E and F). Both comparisons showed distinction between the treatment methods based on PCA (Fig. 2A and B). Comparison between the two cell lines demonstrated that there are almost five times as many genes that show differential expression in T47D breast cancer cells compared to MCF-7 breast cancer cells, while the ratio of up- and down-regulated gene expression is similar in both cell lines (MCF-7 100 genes up, 113 gene down; T47D 447 gene up and 425 down). Unsupervised cluster analysis demonstrated gene expression changes in MCF-7 and T47D breast cancer cells (Fig. 2C and D). Volcano plots between differences in expression levels and significant show high levels of expression changes with relatively low levels of significance in MCF-7 cells (Fig. 2E), while T47D cells demonstrate higher levels of significance on the expression of several genes (Fig. 2F).

Differential gene expression in low glucose environments with BHB treatment. Next, we examined the effect of BHB supplementation on gene expression in MCF-7 and T47D breast cancer cells. The comparisons in this analysis were comparing either $225 \mathrm{mg} / 1$ glucose-treated cells with $225 \mathrm{mg} / \mathrm{ml}$ glucose and $10 \mathrm{mM}$ BHB-treated cells, or $225 \mathrm{mg} / \mathrm{l}$ glucose-treated cells with $225 \mathrm{mg} / \mathrm{ml}$ glucose and $25 \mathrm{mM}$ BHB-treated cells for both MCF-7 and T47D cells. One of the samples for MCF-7 breast cancer cells treated with $5 \%$ glucose and $10 \mathrm{mM}$ BHB failed during library creation, thus this treatment has only a single replicate (Fig. 3A). For MCF-7 cells we observed 163 differentially expressed genes after treatment with $10 \mathrm{mM}$ BHB (Fig. 3E) and 177 differentially expressed genes after treatment with $25 \mathrm{mM}$ BHB (Fig. 3F). Since we did not observe any ontological clustering for MCF-7 glucose deprived breast cancer cells treated with $25 \mathrm{mM} \mathrm{BHB}$ (Fig. 4), the 25 most upregulated (Fig. 3I and J) and downregulated (Fig. 3M and N) genes are displayed. In total we observed 14 differentially expressed genes with BHB treatment in both 10 and $25 \mathrm{mM}$ BHB treated groups (Fig. 3Q). Metabolically interesting is the increased expression of PRPSAP2, which codes for a protein associated with ribosyl-phosphate production (38).

For T47D cells we observed 156 differentially expressed genes after treatment of glucose deprived cells with $10 \mathrm{mM}$ BHB (Fig. 3G) and 394 differentially expressed genes after treatment with $25 \mathrm{mM}$ BHB (Fig. 3H). Despite the number of changes in genes expression, similar to MCF-7 cells, there were no clusters identified in glucose deprived T47D cells following treatment with wither 10 or $25 \mathrm{mM} \mathrm{BHB}$. The 25 most upregulated (Fig. 3K and L) and downregulated (Fig. 3O and P) are displayed. In total we found 40 differentially expressed genes with BHB treatment in both 10 and $25 \mathrm{mM}$ BHB treated groups (Fig. 3R).

Glucose deprivation increases expression of HIPPO pathway inhibitors. When we performed gene ontology, in MCF-7 cells genes that were significantly increased in expression associated with the Hippo-Yap signaling pathway (Fig. 4A) after glucose deprivation (comparison 1), while down-regulated genes were not associated with any pathway. Interestingly gene ontology analysis also indicated that genes that were upregulated when glucose starved cells were compared to those supplemented with $10 \mathrm{mM} \mathrm{BHB}$ (comparison 2) returned the Hippo signaling pathway (Fig. 4B), however only one gene (LATS1) was responsible for this result. Since we did not find the same results after treatment with $25 \mathrm{mM}$ BHB (comparison 3), we did not follow up on this discovery. We downloaded the WikiPathway No. WP4540 to Cytoscape and superimposed the results from comparison 1 for MCF-7 cells. Glucose deprivation of MCF-7 breast cancer cells lead to a decrease in Hippo signaling due to the higher expression of LATS2 and the reduced expression of YAPI and TAZ (Fig. 4C). Additionally, several members of pathways interacting with the Hippo pathway are identified as being differentially expressed in glucose deprived MCF-7 cells such as TEAD1, and the reduced expression of members of the AMPK pathway. 

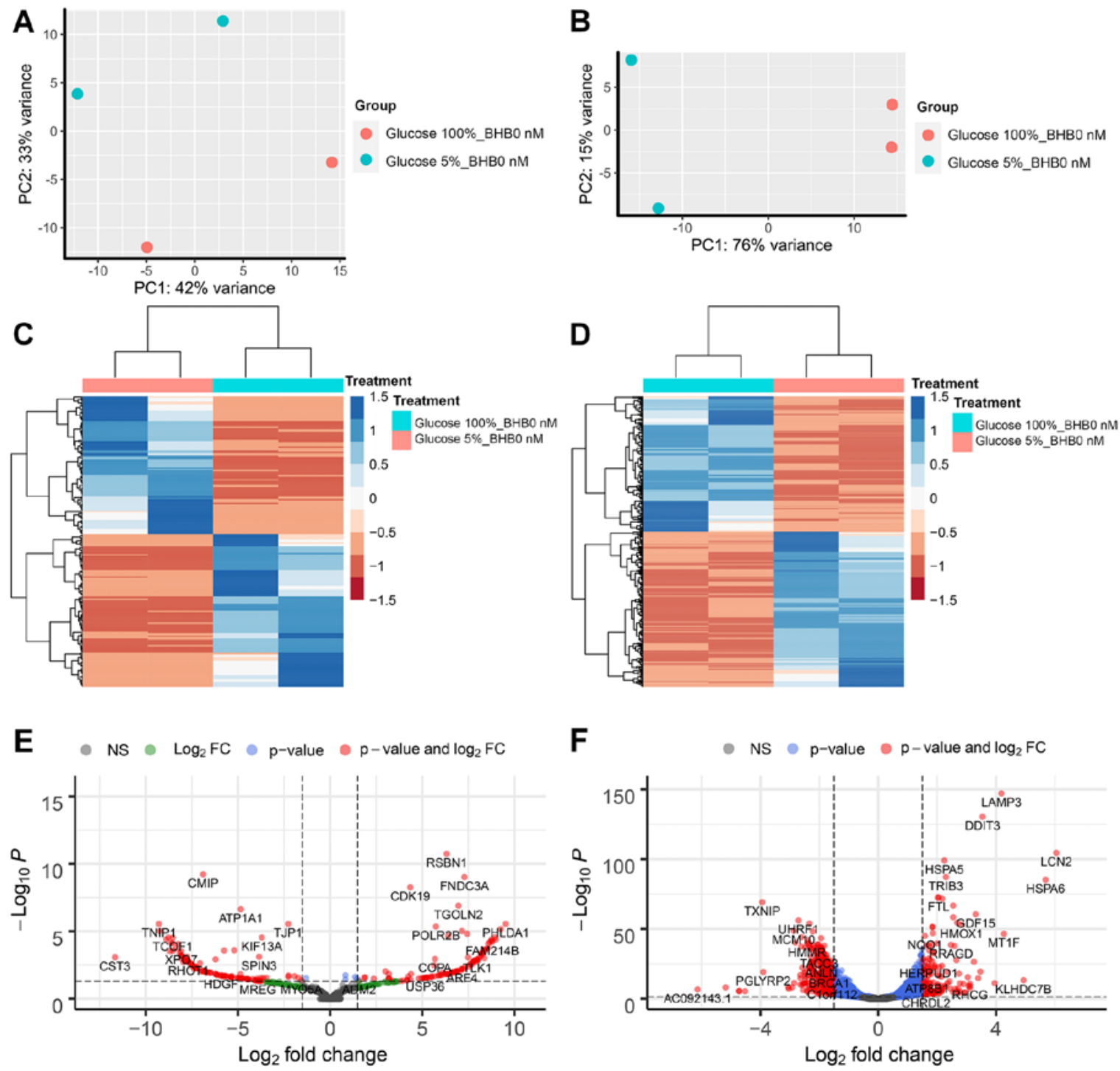

Figure 2. RNA sequencing analysis of MCF-7 and T47D breast cancer cells after glucose deprivation. Principle component analysis of (A) MCF-7 cells and (B) T47D) cells. Unsupervised clustering analysis and heatmap of differentially expressed genes in (C) MCF-7 and (D) T47D cells after glucose deprivation. Volcano plot of differentially expressed genes in (E) MCF-7 cells and (F) T47D cells. Vertical dotted lines indicate borders for genes with 1.5-fold expression change; horizontal dotted line indicates P-value of 0.05 . BHB, $\beta$-hydroxybutyrate.

Glucose deprivation activates ferroptosis in T47D breast cancer cells. In T47D breast cancer cells, gene ontology indicated different pathway involvements for comparison 1 between normal glucose and low glucose treatments. Genes with increased expression after glucose deprivation clustered around the NRF2 pathway, regulation of ferroptosis and unfolded protein response (Figs. 4D and 5A). Within differentially regulated genes around the NRF2 pathway there is increased expression of SLC2A1, the gene coding for the glucose transporter GLUT1 as well as other members of the solute carrier family (SLC5A3, SLC6A9, SLC3A2, SLC7A11). Additionally, several genes regulating ferroptosis showed increased expression, indicating that T47D cells may be susceptible to this unusual cell suicide pathway following glucose deprivation. Genes that showed decreased expression after glucose deprivation are primarily involved in cell cycle control and DNA replication (Figs. 4E and 5B). This is in line with the finding of decreased proliferation in Fig. 1D and E.
Expression of enzymes that catalyze ketone body catabolism in MCF-7 and T47D cells and patient samples. Ketone body catabolism transforms BHB to Acetyl-CoA for immediate oxidation in the TCA cycle (Fig. 6A). The enzymes responsible for this process are BDH, OXCT and ACAT, with OXCT being the rate limiting step in the process. When we extracted the expression results of these genes, we did not find any significant difference in their expression with any treatment (Table SI). Using fragments per kilobase per million mapped reads (FPKM) to provide a means of comparing expression levels, OXCT1 expression is higher in MCF-7 cells than in T47D cells and vice versa for BDH1 expression. In cBioPortal 32 studies with samples from 10953 patients were selected spanning 32 cancer sites and queried for gene expression of BDH1 (Fig. 6B), OXCT1 (Fig. 6C), and ACAT1 (Fig. 6D). All genes showed high expression levels in all queried cancer types. Testicular cancer samples were consistently the lowest expressing samples for all three genes. Interestingly, liver cancer samples showed high expression 

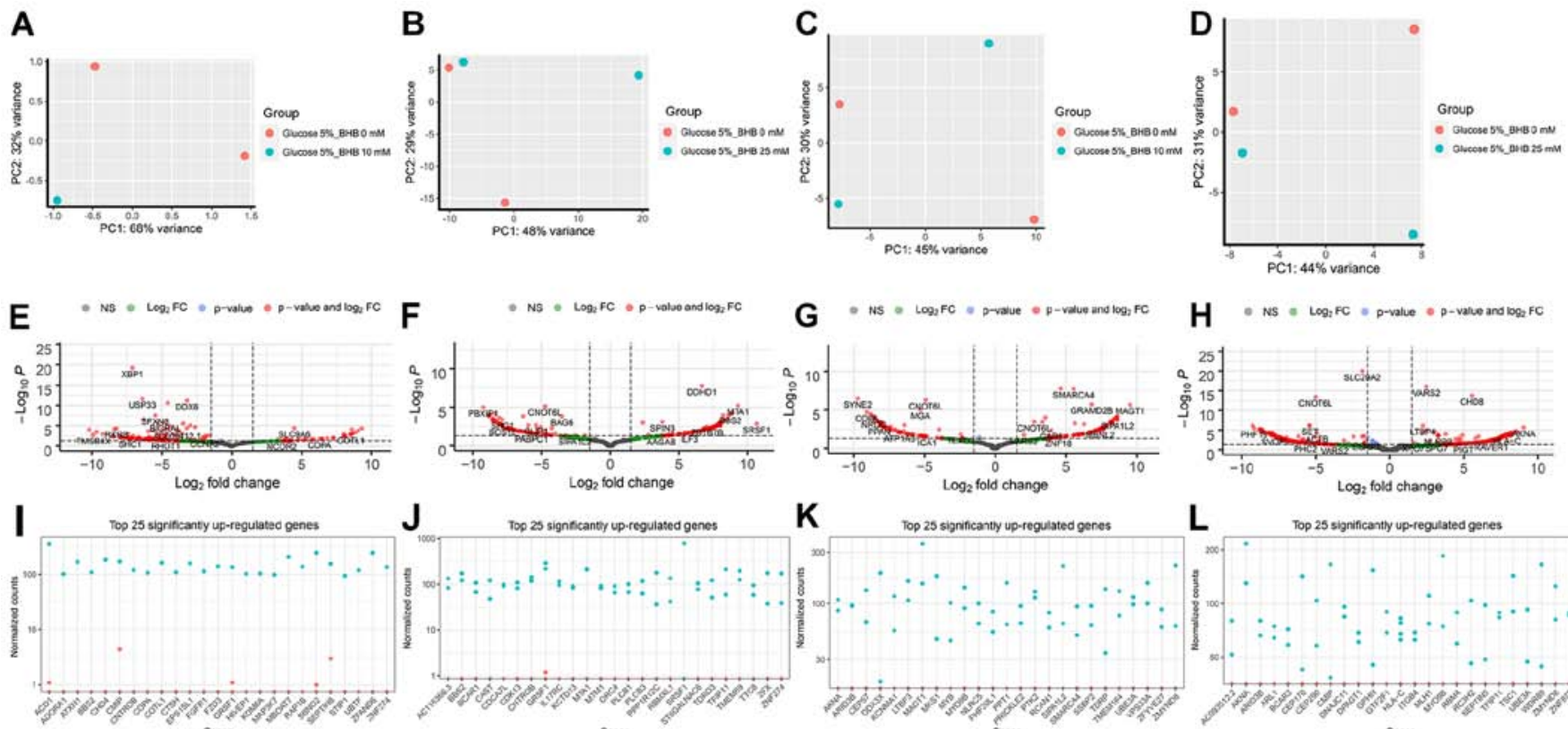

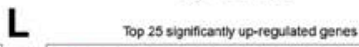

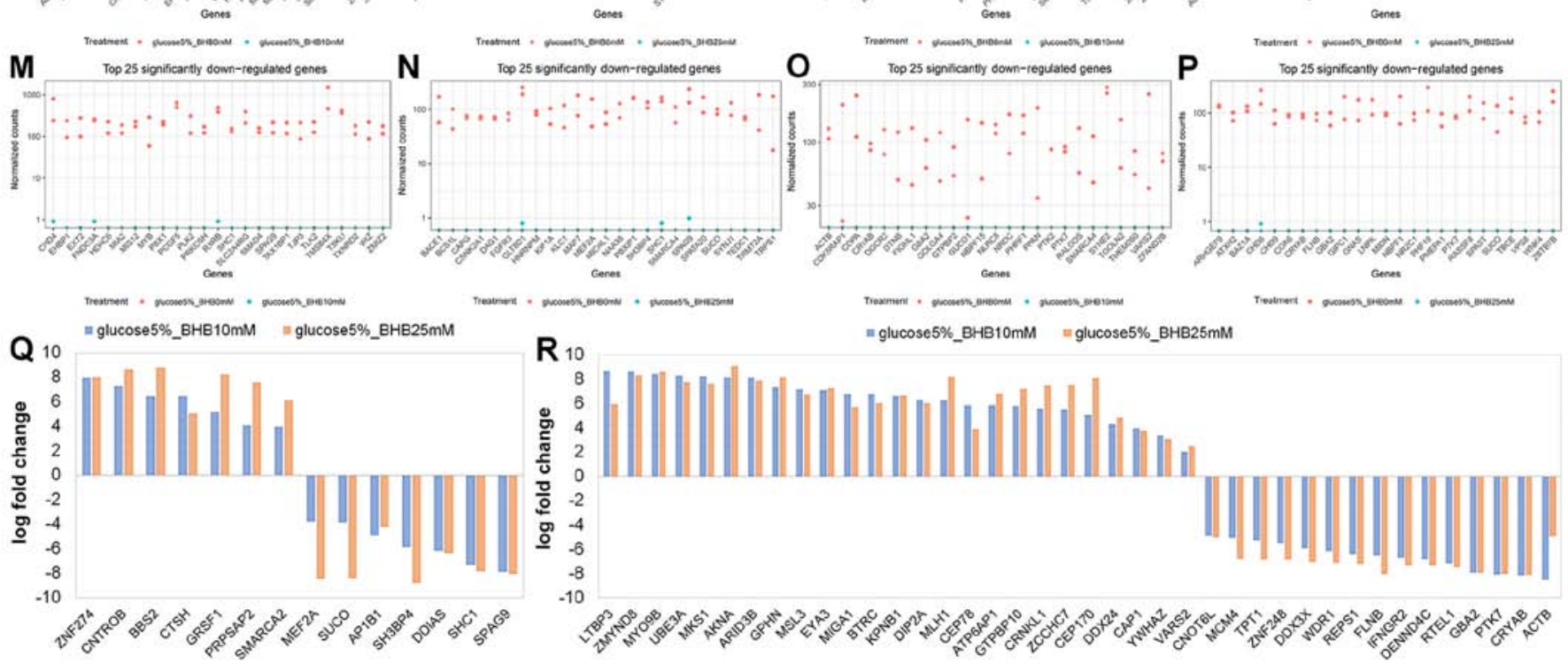

Figure 3. RNA sequencing analysis after $10 \mathrm{mM}$ BHB or $25 \mathrm{mM}$ BHB treatment of glucose deprived MCF-7 and T47D breast cancer cells. Principle component analysis of (A and B) MCF-7 cells and (C and D) T47D cells treated with (A and C) $10 \mathrm{mM} \mathrm{BHB}$ or (B and D) $25 \mathrm{mM}$ BHB compared to cells treated with $225 \mathrm{mg} / 1$ glucose. Volcano plot of differentially expressed genes in (E and F) MCF-7 cells and (G and H) T47D cells treated with (E and G) $10 \mathrm{mM}$ BHB or $(\mathrm{F}$ and $\mathrm{H}) 25 \mathrm{mM}$ BHB compared to cells treated with $225 \mathrm{mg} / 1$ glucose. Vertical dotted lines indicate borders for genes with 1.5 -fold expression change; horizontal dotted line indicates P-value of 0.05 . Highest fold change of differentially expressed genes in (I, J, M and N) MCF-7 cells and (K, L, O and P) T47D cells treated with (I, K, M and O) $10 \mathrm{mM}$ BHB and (J, L, N and P) $25 \mathrm{mM}$ BHB compared to cells treated with $225 \mathrm{mg} / \mathrm{l}$ glucose; Graphs are separates by (I-L) significantly upregulated or (M-P) significantly downregulated gene expression. Genes that are significantly differentially expressed in (Q) MCF-7 cells and (R) T47D cells in both $10 \mathrm{mM}$ BHB and $25 \mathrm{mM}$ BHB treatments. BHB, $\beta$-hydroxybutyrate.

of BDH1 and ACAT1, but the lowest expression of OXCT1. Meanwhile renal cell carcinoma patient samples consistently showed high expression among all three genes. Among all patient samples though BDH1/2 and OXCT1/2 enzymes tended to be co-expressed (Table SII). Genetic or chromosomal mutations of either BDH1 (624/10953), or OXCT1 (377/10953), or ACAT1 (173/10953) in patient samples was a rare occurrence (Fig. 6B-D).

Next, we selected the Breast Invasive Carcinoma (TCGA, PanCancer Atlas) database in cBioPortal and queried the database for gene expression levels of above 1.5 -fold or below -1.5-fold change based on mRNA expression z-scores relative to all samples. Low and high expression of BDH1 (Fig. 6E),
OXCT1 (Fig. 6F), and ACAT1 (Fig. 6G) were plotted against overall survival. High expression of BDH1 or ACAT1 was significantly correlated with lower survival, while there was no significant difference in survival between low and high OXCT1 expressing breast cancer tumors. In fact, there is a non-significant trend to higher survival for patients with tumors overexpressing OXCT1.

\section{Discussion}

Metabolic alterations during cancer etiology are essential for carcinogenesis and have been identified as an emerging hallmark of all cancers (39). At the time of writing there are four 

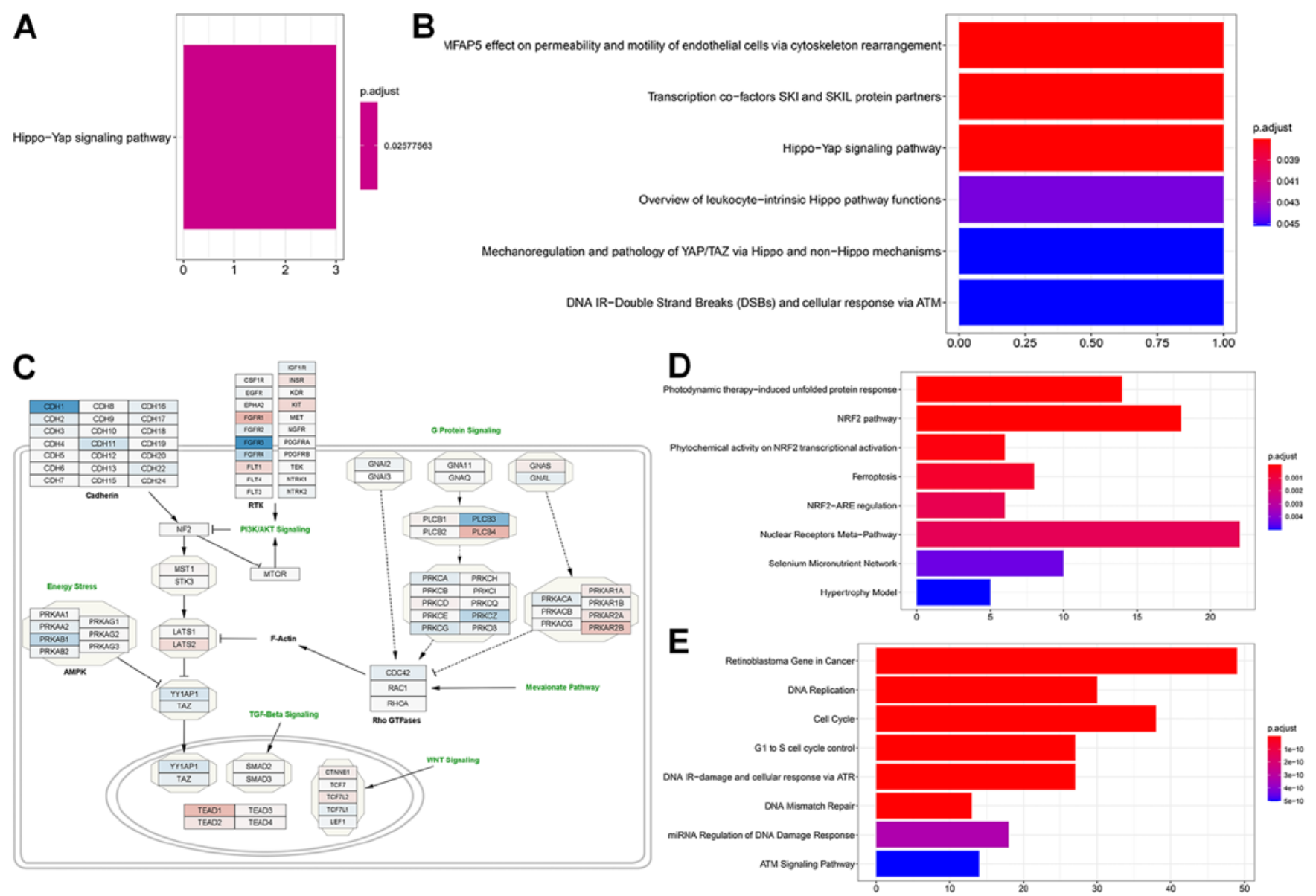

Figure 4. Gene ontology, over representation analysis and pathway enrichment analysis. (A) MCF-7 cells enrichment after glucose deprivation and (B) after treatment with $10 \mathrm{mM}$ BHB compared to cells treated with $225 \mathrm{mg} / 1$ glucose alone. (C) WikiPathways regulating Hippo signaling (WP4540) overlaid with fold-change differentially expressed genes in MCF-7 cells after glucose deprivation compared to cells grown with 4.5 g/l glucose (blue, downregulation; red, upregulation). (D) Over representation analysis results for significantly higher expressed genes in T47D cells after glucose deprivation and (E) for significantly lower expressed genes. BHB, $\beta$-hydroxybutyrate.

clinical trials registered at clinicaltrials.gov that resulted from a query of 'breast cancer' and 'ketogenic diet' and seven trials when queried for 'breast cancer' and 'low carbohydrate'. This demonstrates that dietary intervention trials for the treatment of breast cancer is of interest. The molecular actions of ketone bodies on breast cancer cells during low glucose have not been elucidated. This is important because breast cancer cells may start metabolizing ketone bodies, instead of their preferred fuel glucose, under these conditions. In the presented study we aimed to determine the effects of $\mathrm{BHB}$, the main circulating hepatic ketone body during starvation or ketogenic diets, on two breast cancer cell lines in low glucose conditions.

Reduction in glucose availability decreased proliferation in breast cancer cells. Similarly, glucose restrictions affected breast cancer cells in vitro in long term glucose deprivation experiments (40). We did not observe any changes in cell proliferation when breast cancer cells were treated with BHB in low glucose conditions (Fig. 1G). For breast cancer cells it was observed that BHB treatment decreased cell proliferation further than glucose deprivation alone. The only exception was for T47D cells with $125 \mathrm{mg} / \mathrm{l}$ or $0 \mathrm{~g} / \mathrm{l}$ glucose after $48 \mathrm{~h}$ treatment. However this effect was no longer observed when treatment times were extended to $72 \mathrm{~h}$. Similar results were observed for BT20, BT474, HBL100, MCF-7, MDA-MB 231,
MDA-MB 468, and T47D breast cancer cells under hypoxic conditions (15). Glucose deprivation may be useful in reducing the growth of breast tumor and a ketogenic approach can be utilized for this purpose since breast cancer cells do not seem to increase proliferation in high ketone body environments. It can also be concluded that this effect is specific to cancer cells, since treatment of MCF-10A breast epithelial cells showed higher proliferation with BHB supplementation than without during glucose deprivation.

In MCF-7 breast cancer cells, we found that genes with decreased expression clustered around the Hippo-Yap cell signaling pathway when glucose was removed from the medium. Interestingly pathway enrichment analysis demonstrated that LATS1/2 was further decreased in expression when we compared $10 \mathrm{mM}$ BHB with no BHB supplementation in glucose deprived MCF-7 breast cancer cells. The Hippo-Yap pathway is a conserved pathway involved in organ growth originally discovered in Drosophila. This pathway is a kinase cascade that is activated by G-protein coupled receptors which results in Merlin/NF-2 activation. The signal is further transduced through SAV1-MST1/2 complexes (human ortholog to Drosophila's Hippo) and LATS1/2 before ending in inactivation of YAP/TAZ transcription factors. When active these translocate to the nucleus and dimerize with TEAD1/2 or 


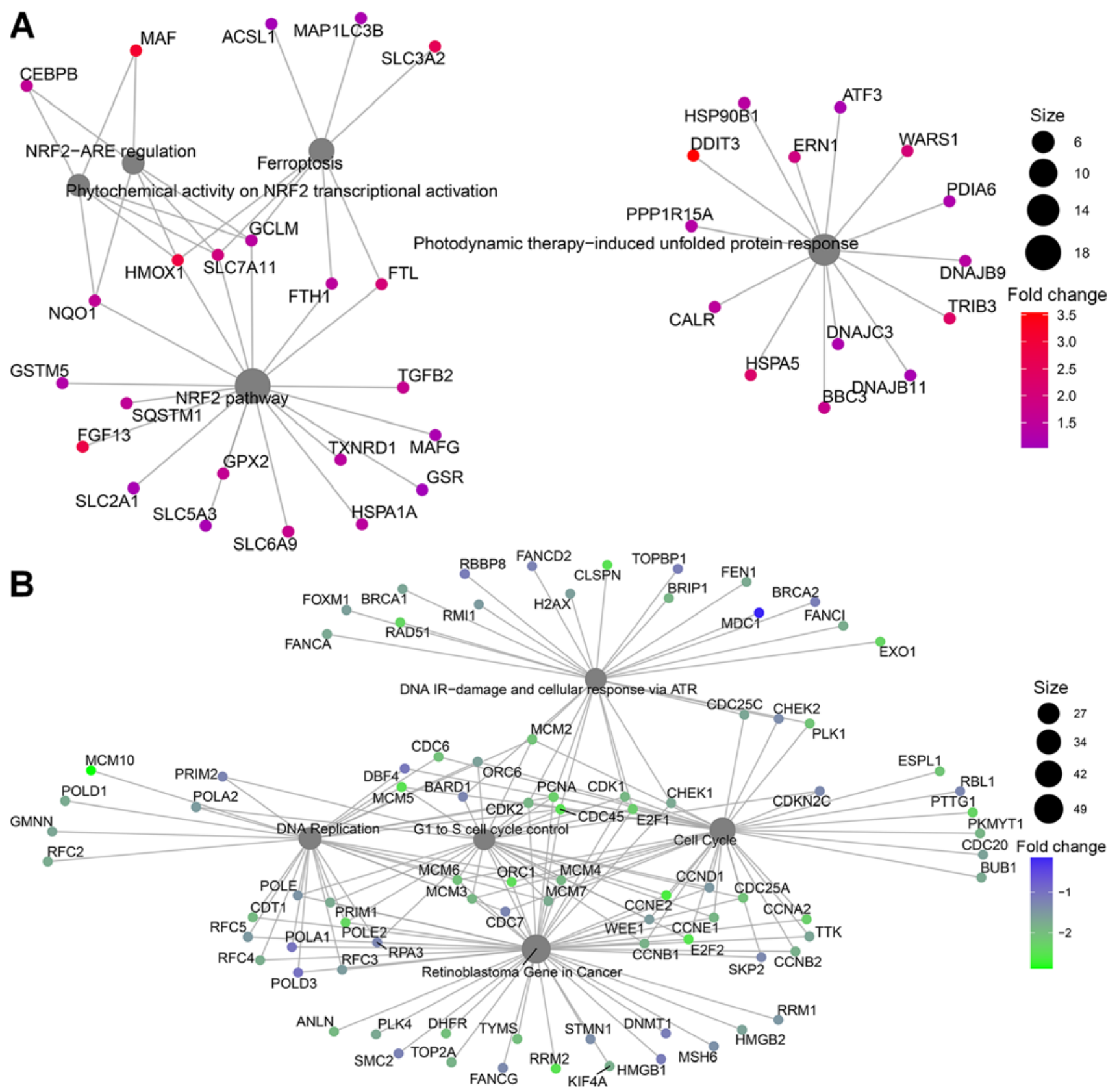

Figure 5. Pathway enrichment analysis of (A) significantly higher expressed genes and (B) significantly lower expressed genes in T47D cells after glucose deprivation.

other co-activators (41). It has been implicated in cancer growth and includes the known tumor suppressor gene NF-2 (42) and implicates a TEAD1 mutation in excessive lesions retina and optical nerve leading to a rare autosomal dominant disease called Sveinsson's chorioretinal atrophy (SCRA) (43). The Hippo pathway transcription factor targets YAP/TEAD have recently been found to accumulate in the nucleus of trastuzumab resistance HER2-positive breast cancer patient samples (44). Additionally, YAP activation was implicated in FAK mediated development of triple-negative breast cancer cells (45). Metabolically the inactivation of the Hippo pathway is involved in maintaining and mediating glucose metabolism in breast cancer cells (46-48). Based on our findings and the supporting literature the Hippo pathway may be involved in mediating the aerobic glycolysis phenotype at least in $\mathrm{MCF}-7$ breast cancer cells.
In T47D breast cancer cells glucose deprivation increased gene expression of genes associates with the NRF2-Ferroptosis axis. Ferroptosis is a recently discovered pathway of programmed cell death driven by iron-dependent lipid peroxidation and distinct from other forms of apoptosis. Cell death is caused by iron mediated lipid reactive oxygen species accumulation exceeding the cell's antioxidant defenses $(49,50)$. Activation of ferroptosis following glucose deprivation in breast cancer cells has not been shown previously and the mechanistic induction is open to speculation. However, several approaches have been used to induce ferroptosis in pancreatic cancer cells (51), hepatocellular (52), and breast cancer cells (53).

One way in which ferroptosis can be activated is through the NRF2 pathway, which our data indicates is activated in response to glucose deprivation in T47D breast cancer cells. 
A<smiles>CC(O)CC(=O)[O-]</smiles>

$\beta$-hydroxybutyrate

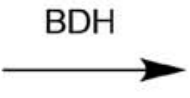

ACAT $1 / 2$<smiles>CC(=O)OC(=O)CCCCCSC(C)=O</smiles><smiles></smiles>

Acetyl-CoA
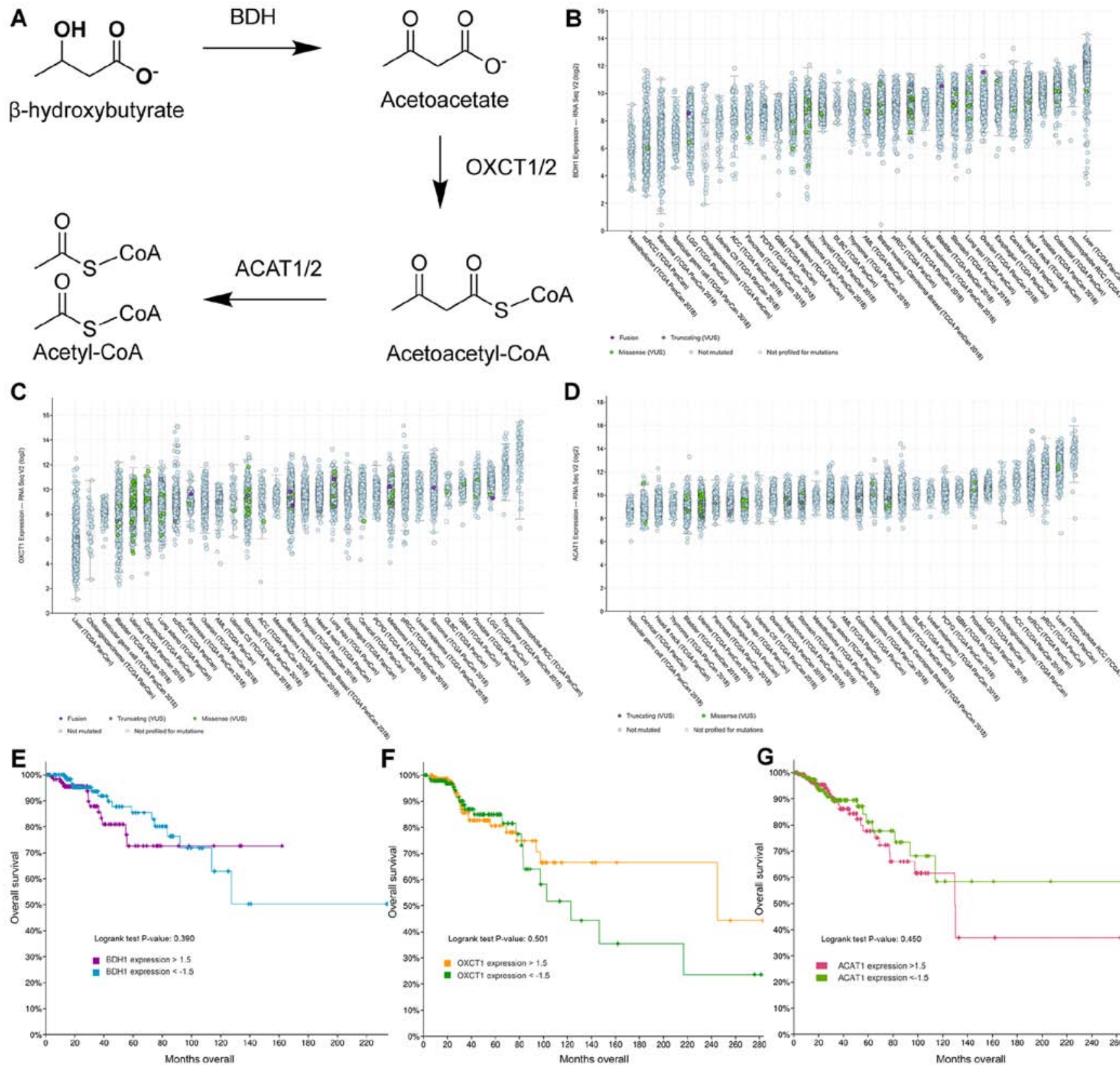<smiles>CC(=O)CC(=O)SC(C)=O</smiles>

Acetoacetyl-CoA

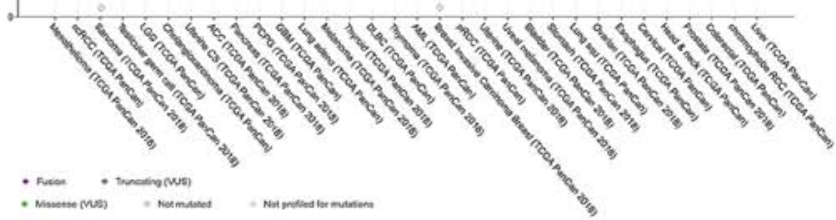

D
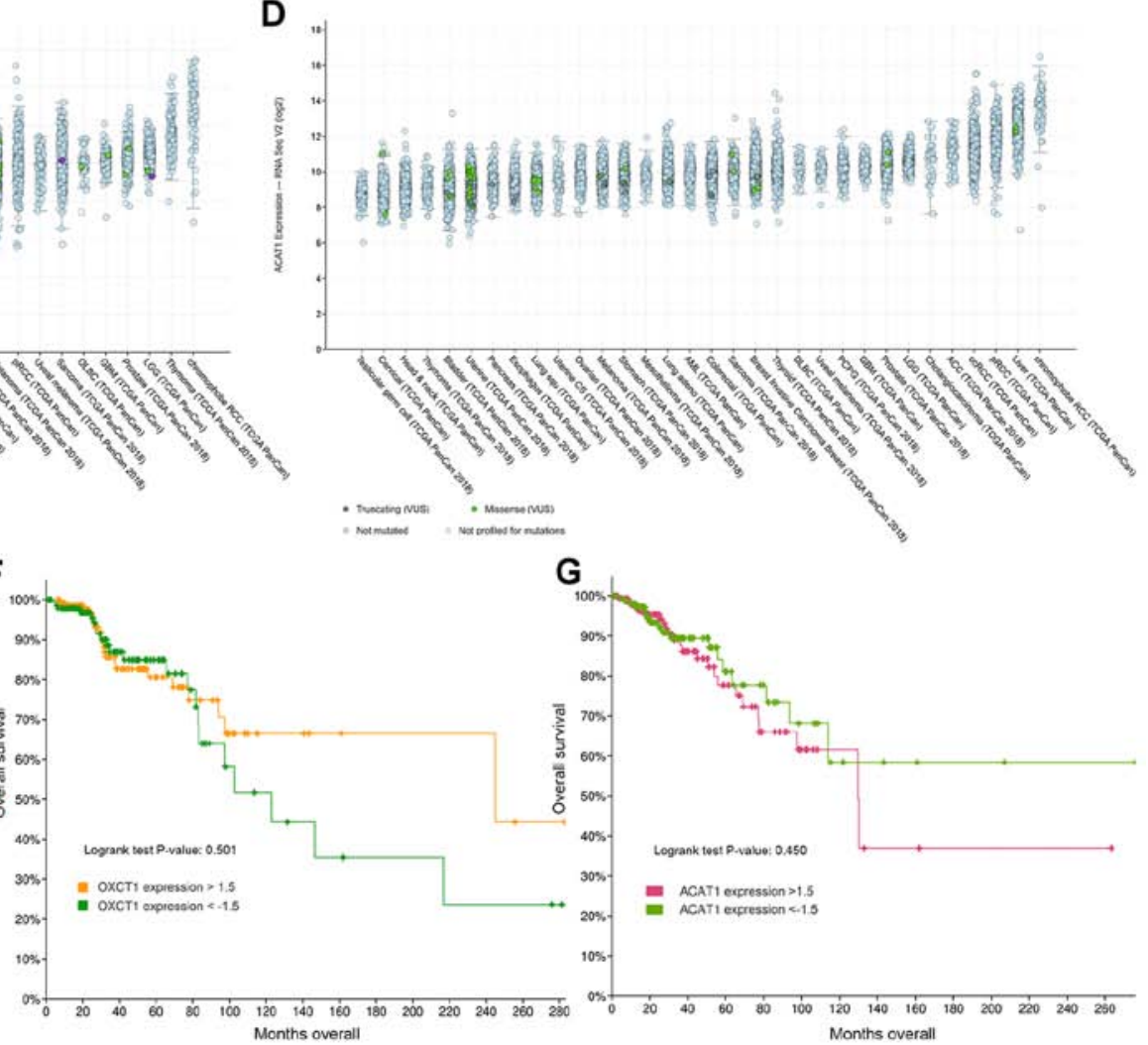

Figure 6. Expression of enzymes responsible for catabolic metabolism of ketone bodies in cancer patient samples. (A) Schematic overview of catabolism of ketone bodies BHB and acetoacetate in neural and peripheral tissues. (B-D) $\log _{2}$-fold gene expression in 32 different cancer sites of (B) BDH1, (C) OXCT1, and (D) ACAT1. Each dot represents the expression level of a single patient. Colors represent gene or chromosomal mutations as labelled in each figure. Cancer studies are ordered by median expression within each study. A total of 10,953 patient samples are represented in these graphs. (E-G) Gene expression levels of above 1.5-fold or below -1.5-fold change based on mRNA expression z-scores relative to all samples are represented from breast cancer patients only and plotted against overall survival for (E) BDH1, (F) OXCT1 and (G) ACAT1.

Indeed, previous studies found that NRF2 protein levels increased in glucose deprived T47D breast cancer cells and knockdown of NRF2 impaired survival during glucose deprivation (54). Thus, it may be possible that glucose deprivation activated NRF2 signaling as a protective measure against increased autophagic flux, while simultaneously increasing ferroptosis.

In glucose deprived breast cancer cells treated with different levels of BHB we did not find any pathways associated with the treatment. We propose this as another incremental evidence that breast cancer cells do not or cannot utilize ketone bodies for their metabolic functions and support the use of ketogenic diets in cancer therapy.
T47D and MCF-7 breast cancer cells were chosen for this analysis since both are luminal A breast cancer subtype and it was expected that their reaction to glucose deprivation would be similar. However, T47D cells reacted by significantly changing 1182 genes compared to 221 genes for MCF-7. Additionally, MCF-7 cell's proliferation remained at $\sim 50 \%$ without any glucose for up to $72 \mathrm{~h}$ (Fig. 1A). When the incubation time was extended up to 18 days, MCF-7 cells showed no difference in proliferation between any of the treatment groups (Fig. 1G). Compared to T47D cells, MCF-7 cells are therefore more resistant to glucose deprivation and it can be suggested that they are utilizing an alternative metabolic fuel. Our results rule out that MCF-7 cells utilize BHB as 
fuel and we suggest that the alternative could be glutamine. We retained glutamine in the medium, since most ketogenic diets do not include reduction in protein intake and may even promote increased protein intake in order to increase satiety and palatability of ketogenic diets (55). In other works, glutamine deprivation of $\mathrm{MCF}-7$ cells resulted in decreased proliferation and increased apoptosis $(56,57)$, supporting this assertion. It was also observed that genes coding for enzymes able to metabolize ketone bodies to acetyl-CoA are expressed in our breast cancer cells (Table SI) and that patient samples indicate decreased survival in patients with tumors expressing high levels of BDH1 and ACAT1. Thus while the breast cancer cells in this study are not utilizing $\mathrm{BHB}$ as energetic substrate, the inherent ability of cells to sustain energetic requirements through a number of different metabolic fuels mandates fuller investigation into the metabolic patterns that breast cancer cells display before engaging in therapeutic interventions. It may be catastrophic to alter diets of cancer patients that inadvertently provide their tumors with a metabolic fuel, including glutamine and BHB, they are adapted to consume.

We aimed to elucidate the gene expression changes that occur when breast cancer cells are adapting their metabolism to a ketogenic environment and are required to use BHB as an energetic metabolite. However, some of the observed gene expression changes may be due to a secondary function of BHB, i.e. its ability to act as a signaling molecule $(21,58,59)$. While the signaling ability of BHB has primarily been demonstrated to activate the starvation response, it is possible that BHB may have effects on breast cancer cells independently of its role as energetic substrate, which may explain some of the changes we have observed. This may in part explain why a substantial number of genes were differentially expressed in glucose deprived cells treated with BHB, without demonstrating any known cell signaling pathway involvement.

In conclusion, glucose deprivation through ketogenic diets may provide a useful tool in battling breast cancer. Similar to a recent study (15), we did not observe any effect of BHB on cell proliferation in breast cancer cells, suggesting that breast cancer cells are unable to use BHB as a fuel to drive proliferation. However, it may be necessary to screen patients for the presences of ketone catabolic enzymes OXCT1/2, $\mathrm{BDH} 1 / 2$, and ACAT1/2, which show increased expression in a variety of patient samples. A ketogenic diet may be disastrous for this subgroup of patients. Additionally, further research is required to understand the different responses we observed in just two breast cancer cell lines to glucose deprivation. This heterogeneity in breast cancer cells will likely impact the ongoing clinical trials using ketogenic diets and possibly lead to dismissing ketogenic diets for cancer treatments, when there might be a substantial subgroup of patients that will benefit from this intervention.

\section{Acknowledgements}

The authors would like to thank Dr Dirk Geerts (Department of Medical Biology, Academic Medical Center Amsterdam, Amsterdam, Netherlands) for consulting on the experimental conditions for the RNA sequencing samples and the Epigenetics Core (Department of Native Hawaiian Health, John A. Burns
School of Medicine, University of Hawai'i at Manoa, Honolulu, HI, USA) for consultation on the RNA sequencing analysis. The authors would also like to acknowledge undergraduate interns Mr. Colin Andres-Paguirigan, Ms. Alyssa Sato, Ms. Leslie Ann Villanueva and Ms. Chanya Techasurungkul (School of Natural Sciences and Mathematics, Chaminade University of Honolulu, Honolulu, HI, USA).

\section{Funding}

This study was funded by a grant from the Alana Dung Research Foundation. MW received pilot funding from the National Institutes of Health (NIH), National Institute of General Medical Sciences (NIGMS), IDeA Networks of Biomedical Research Excellence (INBRE), Award no. P20GM103466.

\section{Availability of data and materials}

The sequencing datasets generated for this study can be found in the Gene Expression Omnibus (GEO) DataSets (https://www.ncbi.nlm.nih.gov/gds) under the accession no. GSE153830. Cell proliferation datasets are available from the corresponding author upon reasonable request.

\section{Authors' contributions}

Conception and design of the study: RM, CAT and MW. Acquisition of data: RM, CAT, CS, AD, KU and MW. Analysis and interpretation of data: RM, AD, KU, CAT and MW. Drafting the manuscript: RM, KU and MW. All authors read and approved the manuscript and agree to be accountable for all aspects of the research in ensuring that the accuracy or integrity of any part of the work are appropriately investigated and resolved.

\section{Ethics approval and consent to participate}

Not applicable.

\section{Patient consent for publication}

Not applicable.

\section{Competing interests}

The authors declare that they have no competing interests.

\section{References}

1. Warburg O: On the origin of cancer cells. Science 123: 309-314, 1956.

2. Arora R, Schmitt D, Karanam B, Tan M, Yates C and Dean-Colomb W: Inhibition of the Warburg effect with a natural compound reveals a novel measurement for determining the metastatic potential of breast cancers. Oncotarget 6: 662-678, 2015.

3. Warburg $\mathrm{O}$, Wind $\mathrm{F}$ and Negelein E: The metabolism of tumors in the body. J Gen Physiol 8: 519-530, 1927.

4. Nebeling LC, Miraldi F, Shurin SB and Lerner E: Effects of a ketogenic diet on tumor metabolism and nutritional status in pediatric oncology patients: Two case reports. J Am Coll Nutr 14: 202-208, 1995.

5. Li Z and Heber D: Ketogenic diets. JAMA 323: 386, 2020. 
6. Bueno NB, de Melo IS, de Oliveira SL and da Rocha Ataide T: Very-low-carbohydrate ketogenic diet v. low-fat diet for long-term weight loss: A meta-analysis of randomised controlled trials. $\mathrm{Br}$ J Nutr 110: 1178-1187, 2013.

7. Martin-McGill KJ, Jackson CF, Bresnahan R, Levy RG and Cooper PN: Ketogenic diets for drug-resistant epilepsy. Cochrane Database Syst Rev 11: CD001903, 2018.

8. Clifton P, Carter S, Headland M and Keogh J: Low carbohydrate and ketogenic diets in type 2 diabetes. Curr Opin Lipidol 26 594-595, 2015.

9. Masino SA and Rho JM: Mechanisms of ketogenic diet action. In: Jasper's Basic Mechanisms of the Epilepsies. 4th edition. Noebels JL, Avoli M, Rogawski MA, Olsen RW and Delgado-Escueta AV (eds). National Center for Biotechnology Information, Bethesda, MD pp1483-1516, 2012.

10. Erickson N, Boscheri A, Linke B and Huebner J: Systematic review: Isocaloric ketogenic dietary regimes for cancer patients. Med Oncol 34: 72, 2017.

11. Klement RJ: Beneficial effects of ketogenic diets for cancer patients: A realist review with focus on evidence and confirmation. Med Oncol 34: 132, 2017.

12. Klement RJ, Champ CE, Otto $C$ and Kämmerer U: Anti-tumor effects of ketogenic diets in mice: A meta-analysis. PLoS One 11: e0155050, 2016

13. Rieger J, Bähr O, Maurer GD, Hattingen E, Franz K, Brucker D Walenta S, Kämmerer U, Coy JF, Weller M and Steinbach JP: ERGO: A pilot study of ketogenic diet in recurrent glioblastoma. Int J Oncol 44: 1843-1852, 2014

14. Kadochi Y, Mori S, Fujiwara-Tani R, Luo Y, Nishiguchi Y Kishi S, Fujii K, Ohmori $\mathrm{H}$ and Kuniyasu $\mathrm{H}$ : Remodeling of energy metabolism by a ketone body and medium-chain fatty acid suppressed the proliferation of CT26 mouse colon cancer cells. Oncol Lett 14: 673-680, 2017.

15. Bartmann C, Janaki Raman SR, Flöter J, Schulze A, Bahlke K, Willingstorfer J, Strunz M, Wöckel A, Klement RJ, Kapp M, et al: Beta-hydroxybutyrate (3-OHB) can influence the energetic phenotype of breast cancer cells, but does not impact their proliferation and the response to chemotherapy or radiation. Cancer Metab 6: 8, 2018

16. Huang D, Li T, Wang L, Zhang L, Yan R, Li K, Xing S, Wu G, $\mathrm{Hu}$ L, Jia W, et al: Hepatocellular carcinoma redirects to ketolysis for progression under nutrition deprivation stress. Cell Res 26 : $1112-1130,2016$

17. Hao GW, Chen YS, He DM, Wang HY, Wu GH and Zhang B: Growth of human colon cancer cells in nude mice is delayed by ketogenic diet with or without omega-3 fatty acids and medium-chain triglycerides. Asian Pac J Cancer Prev 16: 2061-2068, 2015.

18. Poff AM, Ari C, Arnold P, Seyfried TN and D'Agostino DP Ketone supplementation decreases tumor cell viability and prolongs survival of mice with metastatic cancer. Int J Cancer 135 $1711-1720,2014$

19. Martinez-Outschoorn UE, Lin Z, Whitaker-Menezes D, Howell A, Sotgia F and Lisanti MP: Ketone body utilization drives tumor growth and metastasis. Cell Cycle 11: 3964-3971, 2012.

20. Schwartz KA, Noel M, Nikolai M and Chang HT: Investigating the ketogenic diet as treatment for primary aggressive brain cancer: Challenges and lessons learned. Front Nutr 5: 11, 2018.

21. Newman JC and Verdin E: $\beta$-Hydroxybutyrate: A signaling metabolite. Annu Rev Nutr 37: 51-76, 2017.

22. Dai X, Cheng H, Bai Z and Li J: Breast cancer cell line classification and its relevance with breast tumor subtyping. J Cancer 8 : 3131-3141, 2017.

23. Bray NL, Pimentel H, Melsted P and Pachter L: Near-optimal probabilistic RNA-seq quantification. Nat Biotechnol 34 525-527, 2016

24. Love MI, Huber W and Anders S: Moderated estimation of fold change and dispersion for RNA-seq data with DESeq2. Genome Biol 15: 550, 2014

25. Stephens M: False discovery rates: A new deal. Biostatistics 18 275-294, 2017.

26. Huber W, Carey VJ, Gentleman R, Anders S, Carlson M, Carvalho BS, Bravo HC, Davis S, Gatto L, Girke T, et al: Orchestrating high-throughput genomic analysis with Bioconductor. Nat Methods 12: 115-121, 2015.

27. Gentleman RC, Carey VJ, Bates DM, Bolstad B, Dettling M, Dudoit S, Ellis B, Gautier L, Ge Y, Gentry J, et al: Bioconductor: Open software development for computational biology and bioinformatics. Genome Biol 5: R80, 2004.
28. R Core Team: R: A language and environment for statistical computing. https://www.R-project.org/. Accessed February 10, 2015.

29. SlenterDN, Kutmon M,Hanspers K, Riutta A, Windsor J, Nunes N, Mélius J, Cirillo E, Coort SL, Digles D, et al: WikiPathways: A multifaceted pathway database bridging metabolomics to other omics research. Nucleic Acids Res 46(D1): D661-D667, 2018

30. Gustavsen JA, Pai S, Isserlin R, Demchak B and Pico AR: RCy3: Network biology using cytoscape from within R. F1000Res 8: 1774, 2019.

31. Shannon P, Markiel A, Ozier O, Baliga NS, Wang JT, Ramage D, Amin N, Schwikowski B and Ideker T: Cytoscape: A software environment for integrated models of biomolecular interaction networks. Genome Res 13: 2498-2504, 2003.

32. Benjamini Y and Hochberg Y: Controlling the false discovery rate: A practical and powerful approach to multiple testing. J R Stat Soc B 57: 289-300, 1995

33. Kutmon M, Lotia S, Evelo CT and Pico AR: WikiPathways app for cytoscape: Making biological pathways amenable to network analysis and visualization. F1000 Res 3: 152, 2014.

34. Yu G, Wang LG, Han Y and He QY: ClusterProfiler: An R package for comparing biological themes among gene clusters. OMICS 16: 284-287, 2012.

35. Cerami E, Gao J, Dogrusoz U, Gross BE, Sumer SO, Aksoy BA, Jacobsen A, Byrne CJ, Heuer ML, Larsson E, et al: The cBio cancer genomics portal: An open platform for exploring multidimensional cancer genomics data. Cancer Discov 2: 401-404, 2012.

36. Gao J, Aksoy BA, Dogrusoz U, Dresdner G, Gross B, Sumer SO, Sun Y, Jacobsen A, Sinha R, Larsson E, et al: Integrative analysis of complex cancer genomics and clinical profiles using the cBioPortal. Sci Signal 6: pl1, 2013.

37. VanItallie TB and Nufert TH: Ketones: Metabolism's ugly duckling. Nutr Rev 61: 327-341, 2003.

38. Katashima R, Iwahana H, Fujimura M, Yamaoka T, Ishizuka T, Tatibana $\mathrm{M}$ and Itakura $\mathrm{M}$ : Molecular cloning of a human cDNA for the 41-kDa phosphoribosylpyrophosphate synthetase-associated protein. Biochim Biophys Acta 1396: 245-250, 1998.

39. Hanahan D and Weinberg RA: Hallmarks of cancer: The next generation. Cell 144: 646-674, 2011.

40. Mathews EH, Visagie MH, Meyer AA, Joubert AM and Mathews GE: In vitro quantification: Long-term effect of glucose deprivation on various cancer cell lines. Nutrition 74: 110748, 2020.

41. Badouel $\mathrm{C}$ and McNeill H: SnapShot: The hippo signaling pathway. Cell 145: 484-484.e1, 2011.

42. Araki N, Takeshima $\mathrm{H}$ and Saya $\mathrm{H}$ : Neurofibromatosis type 2 (NF2). Gan To Kagaku Ryoho 24: 1427-1431, 1997 (In Japanese).

43. Fossdal R, Jonasson F, Kristjansdottir GT, Kong A, Stefansson H, Gosh S, Gulcher JR and Stefansson K: A novel TEAD1 mutation is the causative allele in Sveinsson's chorioretinal atrophy (helicoid peripapillary chorioretinal degeneration). Hum Mol Genet 13: 975-981, 2004.

44. González-Alonso P, Zazo S, Martín-Aparicio E, Luque M, Chamizo C, Sanz-Álvarez M, Minguez P, Gómez-López G, Cristóbal I, Caramés C, et al: The hippo pathway transducers YAP1/TEAD induce acquired resistance to trastuzumab in HER2-positive breast cancer. Cancers (Basel) 12: 1108, 2020.

45. Rigiracciolo DC, Nohata N, Lappano R, Cirillo F, Talia M, Scordamaglia D, Gutkind JS and Maggiolini M: IGF-1/IGF-1R/FAK/YAP transduction signaling prompts growth effects in triple-negative breast cancer (TNBC) cells. Cells 9: 1010,2020

46. Enzo E, Santinon G, Pocaterra A, Aragona M, Bresolin S, Forcato M, Grifoni D, Pession A, Zanconato F, Guzzo G, et al: Aerobic glycolysis tunes YAP/TAZ transcriptional activity. EMBO J 34: 1349-1370, 2015.

47. Lin $\mathrm{C}$ and $\mathrm{Xu} \mathrm{X}$ : YAP1-TEAD1-Glut1 axis dictates the oncogenic phenotypes of breast cancer cells by modulating glycolysis. Biomed Pharmacother 95: 789-794, 2017.

48. Zheng X, Han H, Liu GP, Ma YX, Pan RL, Sang LJ, Li RH, Yang LJ, Marks JR, Wang W and Lin A: LncRNA wires up Hippo and Hedgehog signaling to reprogramme glucose metabolism. EMBO J 36: 3325-3335, 2017.

49. Han C, Liu Y, Dai R, Ismail N, Su W and Li B: Ferroptosis and its potential role in human diseases. Front Pharmacol 11: 239, 2020

50. Li J, Cao F, Yin HL, Huang ZJ, Lin ZT, Mao N, Sun B and Wang G: Ferroptosis: Past, present and future. Cell Death Dis 11: 88, 2020.

51. Yamaguchi Y, Kasukabe $\mathrm{T}$ and Kumakura S: Piperlongumine rapidly induces the death of human pancreatic cancer cells mainly through the induction of ferroptosis. Int J Oncol 52: 1011-1022, 2018. 
52. Ou W, Mulik RS, Anwar A, McDonald JG, He X and Corbin IR: Low-density lipoprotein docosahexaenoic acid nanoparticles induce ferroptotic cell death in hepatocellular carcinoma. Free Radic Biol Med 112: 597-607, 2017.

53. Chen MS, Wang SF, Hsu CY, Yin PH, Yeh TS, Lee HC and Tseng LM: CHAC1 degradation of glutathione enhances cystine-starvation-induced necroptosis and ferroptosis in human triple negative breast cancer cells via the GCN2-eIF2 $\alpha$-ATF4 pathway. Oncotarget 8: 114588-114602, 2017.

54. Walker A, Singh A, Tully E, Woo J, Le A, Nguyen T, Biswal S, Sharma D and Gabrielson E: Nrf2 signaling and autophagy are complementary in protecting breast cancer cells during glucose deprivation. Free Radic Biol Med 120: 407-413, 2018.

55. Johnstone AM, Horgan GW, Murison SD, Bremner DM and Lobley GE: Effects of a high-protein ketogenic diet on hunger, appetite, and weight loss in obese men feeding ad libitum. Am J Clin Nutr 87: 44-55, 2008.

56. Gwangwa MV, Joubert AM and Visagie MH: Effects of glutamine deprivation on oxidative stress and cell survival in breast cell lines. Biol Res 52: 15, 2019.
57. Ko YH, Lin Z, Flomenberg N, Pestell RG, Howell A, Sotgia F, Lisanti MP and Martinez-Outschoorn UE: Glutamine fuels a vicious cycle of autophagy in the tumor stroma and oxidative mitochondrial metabolism in epithelial cancer cells: Implications for preventing chemotherapy resistance. Cancer Biol Ther 12: 1085-1097, 2011

58. Newman JC and Verdin E: Ketone bodies as signaling metabolites. Trends Endocrinol Metab 25: 42-52, 2014

59. Rojas-Morales P, Tapia E and Pedraza-Chaverri J: $\beta$-Hydroxybutyrate: A signaling metabolite in starvation response? Cell Signal 28: 917-923, 2016.

This work is licensed under a Creative Commons Attribution-NonCommercial-NoDerivatives 4.0 International (CC BY-NC-ND 4.0) License. 